\title{
BEMERKUNGEN OU BEOBACHTUNGEN? SOBRE AS “obSERVAÇÓES PSiCOlógicas" DE SCHOPENHAUER E RÉE ${ }^{1}$
}

\author{
Vilmar Debona ${ }^{2}$
}

\begin{abstract}
Resumo: O artigo investiga os dois diferentes modelos de "observação psicológica" que Arthur Schopenhauer e Paul Rée elaboraram, enquanto parte de suas filosofias morais, pretendendo elucidar as críticas do último à moralidade e à psicologia empírica do primeiro. Para tanto, num primeiro momento, a investigação pauta alguns dos principais conceitos da filosofia moral schopenhaueriana, para, com isso, especificar os principais momentos da elaboração da referida psicologia empírica e o seu alcance no interior dessa filosofia. Destaca-se o caráter descritivo - mas, ainda assim, moral e crítico - atribuído por Schopenhauer a tal psicologia, no sentido de Psychologische Bemerkungen. Num segundo momento, indicam-se elementos conceituais que permitem pensar a recepção e as críticas de Rée a essa mesma noção, a partir da sua obra Psychologische Beobachtungen, que, mesmo declarada pelo autor como sendo de inspiração schopenhaueriana, apresenta suas "observaçôes" com uma conotação diversa, mediante a recusa de elementos fundamentais daquele pensamento, notadamente no que tange ao âmbito da moralidade.
\end{abstract}

Palavras-Chave: Schopenhauer. Rée. Moral descritiva. Observações psicológicas. Psicologia empírica.

Ao Professor Domenico M. Fazio

\begin{abstract}
${ }^{1}$ Este artigo é parte dos resultados da pesquisa de pós-doutoramento que realizamos na Universidade de São Paulo, entre maio de 2016 e maio de 2017, sobre a temática da natureza das "observaçóes psicológicas” de Schopenhauer e Rée, sob a supervisão da Profa Dra Maria Lúcia Cacciola.

2 Professor e Pesquisador da área de Ética no Departamento de Filosofia e no Programa de PósGraduação em Filosofia da Universidade Federal de Santa Maria (UFSM), Santa Maria, RS - Brasil. (iD https://orcid.org/0000-0002-0411-3358 E-mail: debonavilmar@gmail.com

Cofundador e editor-chefe da Voluntas: Revista Internacional de Filosofia, membro da Seção Brasileira da Schopenhauer-Gesellschaft, pesquisador colaborador do Centro Interdipartimentale di ricerca su A. Schopenhauer e la sua Scuola (Lecce) e membro do núcleo de sustentaçáo do GT Schopenhauer da ANPOF. Autor de Schopenhauer e as formas da razâo (Annablume, 2010) e de Schopenhauer (Ideias \& Letras, 2019), além de vários artigos em periódicos nacionais e internacionais.
\end{abstract}

http://dx.doi.org/10.1590/0101-3173.2019.v42n1.08.p153 


\section{CONSIDERAÇÓES INICIAIS}

Além de elaborar um sistema de metafísica imanente, centralizado em sua noção de vontade como conteúdo essencial e moral do mundo, Arthur Schopenhauer (1788-1860) dedicou muitos textos (publicados em vida ou não) a temas de ordem psicológica e antropológica, assuntos que visavam a corroborar a tese reivindicada por ele como seu epíteto, a primazia da vontade sobre o intelecto. Um significativo aparato dessas consideraçóes situa-se na esfera daquilo que o filósofo (SCHOPENHAUER, 2010, p. 49) denominou "mera psicologia empírica" (bloße empirische Psychologie). Tomada como parte de uma antropologia, essa psicologia moral e descritiva, também tomada como “empírico-pragmática”, figura principalmente em dois capítulos da obra tardia Parerga e paralipomena (tomo II). No capítulo I, intitulado Sobre a filosofia e seu método, encontramos uma breve definição de tal psicologia: tratar-se-ia de um "conhecimento das manifestaçóes e particularidades morais e intelectuais do gênero humano que surge da observação, e nesse sentido, conhecimento também da variedade das individualidades." E um requisito da mesma: ela exigiria "fina observação e espirituosa compreensão." (SCHOPENHAUER, 2010, p. 49). Já no capítulo XXVI da mesma obra, o filósofo apresenta o próprio teor de suas - extensas - "observaçôes psicológicas”, expressão que dá título ao capítulo e abriga descriçóes variadas sobre comportamento humano em geral, caráter, motivos das açôes etc.

Paul Rée (1849-1901)³, um dos pensadores da chamada SchopenhauerSchule (escola de Schopenhauer), ${ }^{4}$ pretendeu levar adiante a ideia de uma psicologia empírica como projeto de uma filosofia moral específica. Em seu pequeno livro de máximas de filosofia moral - sobre amor, açóes dos homens e seus motivos, felicidade, vaidade etc. - intitulado justamente Observaçôes

${ }^{3}$ Para um detalhado estudo biográfico de Rée, cf. a obra do estudioso alemão de Schopenhauer, Ludger Lütkehaus (2001), o livro de Domenico M. Fazio (2005), publicado na Alemanha, sob o título Paul Rée. Philosoph, Arzt, Philanthrop, o qual consiste numa versão do texto publicado na Itália, dois anos antes: Paul Rée: un profilo filosofico (2003), mas também o texto de Hubert Treiber (2004, p. 1-51), que acompanha (como parte da Introdução) a edição crítica organizada por ele das obras completas de Rée: Paul Rée - eine biographische und werkgeschichtliche Skizze.

${ }^{4}$ Sobre o conceito, a história e as dimensōes do que se entende hoje por "Schopenhauer-Schule", conferir os numerosos e robustos trabalhos que estão sendo desenvolvidos pelo Centro di ricerca su Arthur Schopenhauer e la sua scuola, da Università del Salento (Lecce, Itália), por exemplo: 1) La scuola di Schopenhauer: testi e contesti. A cura del Centro interdipartimentale di ricerca su Arthur Schopenhauer e la sua scuola dell'Università del Salento (Lecce: Pensa Multimedia, 2009); 2) Schopenhauer und die Schopenhauer-Schule, Hrsg. von F. Ciracì, D. M. Fazio, M. Koßler (Würzburg: Könnigshausen \& Neumann, 2009); 3) La "scuola" di Schopenhauer. Per la storia di un concetto, de Domenico M. Fazio (2007, p. 35-76); 4) A escola de Schopenhauer, de Domenico M. Fazio (2014, p. 11-36). 
psicológicas (publicação anônima de 1875), é flagrante a constatação de que, não fosse o termo alemão empregado para "observaçóes", ou seja, Beobachtungen, o título seria idêntico àquele do referido capítulo XXVI dos Parerga, registrado como Bemerkungen. Quanto a essa questão em específico, porém, uma investigação paralela dos dois textos, tal como faremos a seguir, poderá indicar o quão relevante seria tomar o uso feito pelos pensadores de termos alemáes diferentes para "observaçôes" (Bemerkungen ou Beobachtungen) como indício ou critério de distinção entre duas propostas de psicologia moral empírica, ao modo da breve indicação de Fazio (2010, p. 53).

Com efeito, embora amplamente conhecido por sua amizade, interlocução e sintonia filosófica com Nietzsche e por ter sido um dos integrantes da "trindade", com Nietzsche e Lou von Salomé5, Rée ostenta um pensamento autônomo, como já elucidaram estudiosos europeus, sobretudo com as pesquisas histórico-críticas de Domenico M. Fazio e de Hubert Treiber. Sua produção filosófica, a qual ainda não despertou a merecida atenção nos meios acadêmicos (não temos notícia de alguma tradução de seus livros para a língua portuguesa $)^{6}$, expressa uma originalidade e uma autonomia que extrapolam a relação com o léxico nietzschiano (TREIBER, 1994)7. Quanto à filiação a

5 Uma detalhada reconstrução das relaçôes entre Nietzsche, Lou Salomé e Rée foi elaborada por Ernst Pfeiffer (1970), amigo de Salomé, sob o título Friedrich Nietzsche, Paul Rée, Lou Salomé. Die Dokumente ihrer Begegnung, obra editada em 1970 e republicada posteriormente, numa edição italiana, acrescida de importantes materiais inéditos desencavados por Mazzino Montinari (1999), em Triangolo di lettere. Carteggio di Friedrich Nietzsche, Lou von Salomé e Paul Rée.

6 Observação: após a escrita e o processo de avaliação pela revista Trans/Form/Ação deste artigo, a Editora Unifesp lançou a tradução de $A$ origem dos sentimentos morais (traduçáo de André Itaparica e Clademir Araldi, São Paulo, 2018).

Muito embora contemos com uma significativa literatura sobre Rée - tanto em nível internacional quanto em nível nacional -, ainda são poucas as pesquisas que o consideram como pensador autônomo e independente da figura e da produção de Nietzsche. De forma semelhante, a literatura sobre Rée como um intérprete ou crítico de Schopenhauer, que não se prende ao filtro de Nietzsche, ainda é escassa, principalmente no Brasil. Na já referida obra Schopenhauer und die Schopenhauer-Schule, pode-se encontrar um capítulo importante de Domenico M. Fazio (2009) intitulado Ein Schopenhauerianer namens Rée. Mas ainda não contamos com trabalhos aprofundados que tratem especificamente da temática Rée-Schopenhauer, com exceção de raros artigos publicados em periódicos, como é o caso de "A ética na escola de Schopenhauer: o caso de Paul Rée", também de Fazio (2012), e "A vaidade em Paul Rée: uma questáo entre Nietzsche e Schopenhauer”, de Bruno Machado (2016b). Os textos brasileiros mais substanciais e detalhados sobre o pensamento de Rée, são, em verdade, sobre sua filiação ou distanciamento em relação a Nietzsche, a exemplo da tese de Bruno Martins Machado (2013), A psicologia em "Humano, demasiado humano": Nietzsche, Paul Rée e a história natural da moral, recentemente publicada como livro: Nietzsche e Rée: psicólogos e espíritos livres (2016a).

7 Somos conscientes das afinidades entre os projetos filosóficos de Nietzsche e Rée da época da elaboração de Humano, demasiado humano (1878), cujas teses coincidem em grande parte com as 
Schopenhauer, importa considerar desde já que a mencionada SchopenhauerSchule (tomada aqui em sentido lato) o classifica na categoria dos "heréticos", pois, apesar de ter-se inspirado no pensamento e em temas de seu mestre, não assumiu grande parte deles, no mesmo sentido. Suas contestaçóes à visão schopenhaueriana de mundo são, de fato, significativamente mais agudas, se comparadas às suas assimilaçóes. Basta mencionarmos, por ora, que a produção de Rée posterior às Observaçóes psicológicas é tida até mesmo como algo "ex-schopenhaueriano", dado que o autor assume fortemente, por exemplo, o evolucionismo de Darwin, para defender suas teses sobre a Origem dos sentimentos morais (1877) e, mesmo quando volta a tratar de temas tipicamente schopenhauerianos, como o da Ilusão da liberdade da vontade, título do seu último livro publicado em vida (1885), a rejeição de hipóteses como a da liberdade transcendental, da imputabilidade moral e do próprio núcleo do pensamento schopenhaueriano - a existência de uma vontade como coisa em si - impede uma proximidade significativa em relação ao filósofo da vontade.

É inegável, porém, que a recusa da metafísica da vontade de $O$ mundo como vontade e representação não impediu a adoção, por parte de Rée, de importantes teses e características da filosofia moral tardia desenvolvida nos Parerga e paralipomena. Com efeito, não apenas a constatação de que os títulos dos referidos escritos são os mesmos, mas principalmente o fato de o intérprete de Schopenhauer ter retirado do outro capítulo dos Parerga mencionado acima (Sobre a filosofia e seu método) o próprio projeto de pesquisa que aplicou em seu livro indica que, de uma forma ou de outra, Rée valorizou as tais observaçóes psicológicas da psicologia empírica schopenhaueriana, tendo seguido o mestre, inclusive, quanto ao uso do gênero aforismático. $\mathrm{O}$ autor de Observaçóes psicológicas teria tornado sua a ideia schopenhaueriana ${ }^{8}$

que temos em Observaçôes psicológicas (1875) e em Origem dos sentimentos morais (1877), embora discordem quanto a outras, como sobre a existência ou não de "impulsos altruísticos" no ser humano. Estamos cientes também quanto à polêmica registrada no epistolário dos dois pensadores sobre a qual dos dois pertenceria a paternidade de importantes teses relativas ao tema dos sentimentos morais, com o consequente rompimento em relaçấo a teses fulcrais de Schopenhauer. Porém, optamos aqui por não considerar o conteúdo e a natureza desse debate, que, como afirmamos na nota anterior, já é bastante contemplado e consolidado por competentes pesquisas, a julgar pela já mencionada tese doutoral de Bruno Martins Machado.

8 Segundo Treiber (2004, p. 415), embora o Schopenhauer de Rée (da época da escrita de Observaçóes psicológicas) "não seja o do Nietzsche da Terceira Consideração Extemporânea (1874), trata-se de um Schopenhauer tomado como determinista e como 'crítico da ética kantiana', assim como o astuto psicólogo (scharfsinniger Psychologe) cujos modelos e métodos são retirados do $\$ 21$ dos Parerga e paralipomena II." 
de uma psicologia empírica e descritiva pautada na observação psicológica das diferentes individualidades, mas também tomou para si a lista de leituras que Schopenhauer elencara daqueles que, no mesmo capítulo Sobre a filosofia e seu método (\$21), chamou de "espíritos superiores": autores como Teofrasto, Montaigne, La Rochefoucauld, La Bruyère, Helvétius, Chamfort, Addison, Shaftsbury, Shenstone, Lichtenberg, entre outros. Na ocasião em que indicou essa lista de leitura, Schopenhauer argumentou, com Kant, a impossibilidade da fundação de uma psicologia racional nos moldes da tradição wolffiana, a qual seria a mesma diretriz seguida por Rée (TREIBER, 2004), enquanto estudioso e debatedor da psicologia empírica de inspiração schopenhaueriana.

É diante disso, pois, que pensamos ser possível debater o estatuto moral das observaçóes psicológicas que ambos os pensadores elaboram. Afinal, por mais que já se saiba, em linhas gerais, o quanto de schopenhaueriano há em Rée, as características fundamentais do seu schopenhauerianismo - para o nosso caso, especificamente aquelas de uma psicologia empírica -, assim como suas críticas a ela são noçôes que ainda precisam ser especificadas.

\section{Pressupostos Da METAFísica E DA MORAL SCHOPENHAUERIANA}

Consideremos, de antemão, alguns elementos da metafísica da vontade e da moral schopenhauerianas, que, mais à frente, servirão também para especificarmos a natureza das observaçóes psicológicas de Rée frente às de seu mestre.

O núcleo em torno do qual se move todo o pensamento de Schopenhauer concebe que a vontade como coisa-em-si, elemento metafísico - em sentido imanente - e primário, consiste numa essência que se objetiva e se afirma nos mais variados fenômenos e reinos da natureza, objetivação que vai da força magnética à consciência humana. No caso do homem, a vontade constitui a esfera subjetiva e essencial da identidade de cada indivíduo, e sua afirmação se dá em forma de instintos e impulsos egoísticos. Já o intelecto, como esfera objetiva, é tido pelo filósofo como mera aparência, cuja existência é secundária e derivada. Mas vontade e intelecto, substância e acidente, matéria e forma constituem uma unidade e, assim, expressam a ideia de um microcosmo num macrocosmo. Mesmo sendo a vontade em si mesma, como essência do mundo, algo sem-fundamento (grundlos), uma essência cega e incessante, ainda teríamos acesso a um fenômeno imediato dela, que é sua mais clara e próxima aparição (Erscheinung), a saber, o ato de vontade enquanto 
vontade humana manifesta em cada caráter individual; este que é tomado, por um lado, como caráter inteligível e, por outro, como caráter empírico.

Um elemento imprescindível para nossa investigação diz respeito justamente à ideia de caráter como impulso irracional e imutável, que permite definir o homem como egoísta e malévolo por natureza, cujos desejos incessantes impedem a sua felicidade e o arremetem aos dois polos do sofrimento, a dor e o tédio. O caráter do homem assim definido compóe aquilo que o filósofo, em um fragmento póstumo de 1826 (1911-1941d, p. 255), chamou de seu "dogma principal" (Hauptdogma) e, em uma carta ao discípulo Julius Frauenstädt, de 06 de junho de 1856, definiu como "a mais importante de todas as verdades" (die wichtigste aller Wabrheiten) (SCHOPENHAUER, 1911-1941e, p. 491-492), o primado da vontade sobre o intelecto, ponto nodal de todo o seu sistema. Esse elemento, aliás, poderia ser considerado, em grande medida, como um pertinente ponto de partida para a definição da psicologia empírica e antirracionalista schopenhaueriana, já que toma o "eu" como uma polaridade composta por vontade inconsciente e por intelecto consciente, uma vontade cega e um intelecto que vigia.

No entanto, para que o caráter seja tomado como impulso irracional, pressupóe-se a "profundidade escura" da vontade (cósmica) enquanto energia vital, instintiva, pulsional (FONSECA, 2012), na qual ele se enraíza. O outro polo característico de cada indivíduo, composto por sua consciência, por seu intelecto, por seus pensamentos claros, por suas cogniçóes e por seus juízos distintos, representaria apenas os ramos da árvore cujas raízes - a vontade -, seria o originário, o perene, também tomado como "o núcleo do nosso ser." (SCHOPENHAUER, 2015, p. 309).

Esse aparato metafísico e psicológico se traduzirá no âmbito da moralidade como a predominância do ser (esse) sobre as açóes (operari), dado que operari sequitur esse, isto é, as açóes seguem-se do ser (enquanto vontade individual, caráter), e não o contrário. E tal ser se definiria a partir de três impulsos fundamentais (Grundtriebfedern) bens específicos, também denominadas "motivaçóes fundamentais" do agir humano: o egoísmo, a maldade e a compaixão ${ }^{9}$. A cada caráter seria intrínseca e invariável uma tendência impulsiva que o definiria e da qual decorreriam suas açóes preponderantes. Mas,

\footnotetext{
9 Em uma breve nota do Capítulo 48 do Tomo II de $O$ mundo como vontade e representaçáo, Schopenhauer chega a considerar brevemente a hipótese da ascese como uma quarta motivação. Sobre essa polêmica temática, cf. Bacelar (2010).
} 
dentre tais motivaçóes, a principal e fundamental, tanto no homem quanto no animal, seria o egoísmo, o ímpeto para a existência e o bem-estar.

Além de reconhecer o egoísmo e a maldade como motivações intrínsecas ao agir humano, Schopenhauer entende a moralidade como inata, constante e impossível de ser ensinada, intensificada ou melhorada, reconhecendo-a unicamente na ação por compaixão, na medida em que esta seja desinteressada e livre de egoísmos. Mas é a própria concepção metafisica de caráter que permite essa defesa: o caráter individual e inato já conteria em si mesmo todo vício e toda virtude, ou seja, ele já traz consigo toda moralidade. E como nas açôes humanas predominam o egoísmo e a maldade, a compaixão só pode ser tomada como uma espécie de milagre, embora não deixe der ser cotidiana. A única via que representaria um rompimento duradouro com o egoísmo interesseiro e intrínseco à natureza humana seria a do ascetismo, uma passagem da virtude para a ascese pela teoria da supressão do caráter, na qual os caracteres são tomados enquanto negadores da vontade.

No $₫ 10$ de Sobre o fundamento da moral, por exemplo, o caráter do indivíduo enquanto fenômeno, o caráter empírico, é adjetivado como imutável, inflexível, "determinado rigorosamente" pela lei de causalidade e expressão do em-si do caráter, no tempo e na sucessão dos atos. Já o caráter inteligível é tomado como inato, fundamento imutável e que determina o caráter empírico, livre em relação ao tempo, à sucessão e à multiplicidade dos atos; natureza fixa, que, todavia, é individual, instância na qual mora a responsabilidade e, com ela, a liberdade.

Vale considerar que o filósofo enaltece a tese de que um tal caráter imutável e detentor das atribuiçóes supra elencadas "é, todavia, bem individual e, em cada um, é outro", a partir do que "o conjunto dos atos [de cada um], de acordo com suas manifestaçóes exteriores, determinadas pelos motivos, nunca poderia acontecer de outro modo" (SCHOPENHAUER, 2001, p. 96); por isso, para um indivíduo dado, e frente a um caso dado, seria possível táo somente uma única e necessária ação. $\mathrm{Na}$ quádrupla adjetivação do caráter, que o toma como individual, empírico, invariável e inato, e que é apresentada no ensaio Sobre a liberdade da vontade, a diversidade moral dos caracteres, perceptível pela observação de que a ação de um mesmo motivo é tão diversa de um homem para outro (muito embora existam linhas gerais que formam uma base em comum de todos) é ilustrada pela metáfora de que "a luz do sol embranquece a película e enegrece o cloreto de prata; e o calor amolece a cera e endurece a argila." (SCHOPENHAUER, 1911-1941c, p. 518). Porém, a 
questão sobre o que vem a ser cada um dos caracteres, mesmo quando estes são tomados como objetidade da vontade impessoal em uma vontade personalística, fica sem uma resposta a priori: "só aprendemos a nos conhecer empiricamente e não temos qualquer conhecimento a priori do nosso caráter." (SCHOPENHAUER, 2001, p. 97). Somente o autoconhecimento, que é desenvolvido pelo pensador nos termos de uma terceira noção de caráter, a do caráter adquirido, pode garantir a consciência do que somos, ou seja, favorece a apreensão do que vem a ser cada microcosmo enquanto parte da infundada vontade macrocósmica. Afora isso, o caráter só pode ser explicado enquanto afirmação da vontade (SCHOPENHAUER, 2005, p. 336) e, se essa vontade é grundlos, sem-fundamento, e "não sabe o que quer", então o caráter específico de cada indivíduo também é privado de razão, pois é parte integrante daquela essência em comum.

Por meio dessa tese, Schopenhauer chega à diferenciação entre o caráter da espécie e o caráter do indivíduo. $\mathrm{O}$ argumento pauta-se na consideração de que o caráter individual do homem só pode ser identificado com mais nitidez após as tomadas de decisóes, que, por sua vez, só se verificam com os atos: "Exclusivamente no homem é a decisão, e não o mero desejo, uma indicação válida de seu caráter, para si mesmo e para os outros [...]. Só o ato é a expressão das máximas inteligíveis de sua conduta." (SCHOPENHAUER, 2005, p. 388). O mero desejo seria indicativo apenas do caráter do homem em geral e, assim, do que este seria capaz de fazer, mas não de cada individualidade.

Dessa forma, o caráter, uma vez que se expressa e se faz conhecer na empiricidade, é tomado em sua relação a mais estreita possível com a fundamentação da moralidade. Em vista dessa relação, é importante considerarmos os seguintes elementos: (i) a partir da observação do que cada caráter é capaz de realizar, a finalidade da ética seria a de "esclarecer, explicar e reconduzir à sua razão última os modos muito diferentes de agir dos homens no aspecto moral" (SCHOPENHAUER, 2001, p. 119); (ii) o único caminho que restaria para "a descoberta do fundamento da ética [...], a saber, o de investigar se há em geral açóes às quais temos de atribuir autêntico valor moral - que seriam as açóes de justiça espontânea, pura caridade e generosidade efetiva [e cuja base seria a compaixão]" (SCHOPENHAUER, 2001, p. 119), seria o caminho empírico. Além disso, (iii) para complementar a definição de sua ética "descritiva", o filósofo salienta que a motivação moral tem de ser positivamente agente, portanto, real; e, "como para o homem só o empírico [...] tem realidade pressuposta, a motivaçáo moral tem de ser empírica e, como tal, 
chegar até nós sem ser chamada" (SCHOPENHAUER, 2001, p. 51). Por fim, (iv) pelo fato de o caráter ser inato e a ação dos motivos fatais, sempre que se apresentarem as mesmas motivaçóes ao mesmo caráter, este produzirá sempre as mesmas açôes de forma necessária e imediata: "[Frente aos mesmos motivos] cada caráter sempre reage do mesmo modo, regular e necessariamente" (SCHOPENHAUER, 2005, p. 388) ${ }^{10}$, ou seja, é constante.

Cabe notar, no entanto, que a caracterologia schopenhaueriana não toma ninguém como totalmente compassivo, totalmente egoista ou totalmente maldoso, mas cada um como detentor de uma determinada parcela das mencionadas Grundtriebfedern, tendências impulsivas fundamentais. Entretanto, quais seriam os "componentes materiais" dessa essência caracterológica humana? Em Sobre a liberdade da vontade, lemos:

Cada um de nós, por pouco que observe (bei Beobachtung) a própria consciência, não tardará a perceber que o objeto dessa faculdade é invariavelmente o seu querer individual; mas por isso [querer individual] não se pode entender somente as voliçôes que imediatamente se traduzem em atos [...]. Quem souber identificar o essencial das coisas [...], não hesitará em reconhecer que cada desejo, aspiração, esperança, amor, alegria etc., assim como os sentimentos opostos, ou seja, a repulsão, o medo, a cólera, o ódio, a tristeza, a dor, numa palavra, todos os afetos e paixóes, deveriam ser considerados manifestaçôes do querer; estes afetos e paixôes não são mais do que movimentos mais ou menos brandos e fortes, ora violentos e tumultuosos, ora calmos e regulares, da vontade individual. (SCHOPENHAUER, 1911-1941c, p. 481, grifo nosso).

Em primeiro lugar, pois, o conteúdo do caráter como vontade individualizada, a ser estudada - ou "observada" - pela psicologia empírica, consistiria em impulsos elementares, desejos e necessidades vitais, instintos primordiais. Em segundo lugar, em sentimentos, afetos e paixóes. E, ainda, diria respeito à complexa composição do que geralmente se chama de personalidade individual, ou seja, respeitaria ao fato de um indivíduo ser calmo, sincero, generoso, ponderado, enquanto outro é impaciente, falso, avarento, egoísta,

\footnotetext{
${ }^{10}$ Nesse sentido, Schopenhauer defende a possibilidade de conhecermos a admirável diferença entre uma pessoa e outra, assim como o caráter de cada uma delas, mediante o acesso a uma única e quimérica ação que lhes corresponda. No Vol. II dos Parerga, por exemplo, o filósofo argumenta que "um botânico conhece a planta inteira por uma folha, e Cuvier construiu o animal inteiro por um osso [...]. Se alguém mostra em tais situaçôes, por seu comportamento absolutamente inescrupuloso e egoísta, que a disposição para a justiça é estranha ao seu coração, não lhe confiemos, sem grande precaução, nenhum centavo." (SCHOPENHAUER, 2012, p. 74).
} 
maldoso. Nas palavras de Gurisatti (2002, p. 91), “o caráter individual [tal como definido por Schopenhauer] pode ser considerado o resultante de uma estratificação complexa e dinâmica, mas também contraditória, de elementos psíquicos heterogêneos, que vão desde o mais elementar e instintivo até o mais complexo e volitivo." Em geral, Schopenhauer sustentará que cada caráter é composto por determinadas parcelas de tendências impulsivas elementares, as quais variam das mais compassivas e bondosas às mais egoístas e maldosas.

\section{A psicologia empírica e as obSerVaÇóes PSicológicas (PSYCHOLOGISCHE BE- MERKUNGEN) DE SCHOPENHAUER}

A noção de psicologia, tratada por Schopenhauer em paralelo ou como parte de uma antropologia, recebe dele conotaçôes diversas, a depender do período em que foi abordada. De maneira geral, podemos reconhecer ao menos três momentos em que, no corpus schopenhaueriano, o tema aparece de forma mais significativa:

1) Em 1813, por exemplo, em sua tese de doutoramento, Schopenhauer argumenta sobre a impossibilidade de um conhecimento completo do caráter empírico, afirmando:

Todavia, até certo ponto um conhecimento do gênero é possível ou até mesmo efetivo e de grande utilidade [von großem Nutzen] para os homens do mundo. Uma diretriz neste campo é oferecida, de um ponto de vista específico, pela psicologia pragmática, e, de um ponto de vista geral, pela psicologia empirica. (SCHOPENHAUER, 1911-1941b, p. 81, grifo nosso).

Um pouco adiante, ao considerar que, no caso dos animais, o caráter da espécie pode ser reconstruído com base nas observaçóes feitas em diversos indivíduos, destaca que, já no caso do homem, "isso dá lugar àquilo que se chama de conhecimento do homem (ou seja, a uma psicologia empírico-pragmática não sistemática), cujas regras, todavia, jamais demonstram certeza, devido ao caráter individual que se sobressai claramente." (SCHOPENHAUER, 19111941 b, p. 82, grifo nosso).

2) Nos Quartant, de 1826 (livro dos Manuscritos Póstumos), principalmente nos $\$ 124$ e 128 , o filósofo concebe que não pode haver "uma psicologia como ciência autônoma", já que os fenômenos psíquicos (pensar e querer) são apenas "efeitos de causas físicas presentes no organismo" (SCHO- 
PENHAUER, 1911-1941d, p. 251-252), requerendo-se, portanto, a fisiologia e a anatomia como condiçóes para quaisquer explicaçóes. Nesse momento, enquanto reprova (assim como no texto dos Parerga) a psicologia racional de inspiração leibniziano-wolffiana, é possível afirmar que Schopenhauer trabalha em um solo "reducionista-materialista", reconhecendo apenas uma fonte fisiológico-anatômica para a psicologia e concebendo uma antropologia que se esgotaria enquanto zoologia ou medicina.

3) De modo muito diverso, porém, nos Parerga, de 1851, a antropologia enquanto "ciência da experiência" divide-se em a) anatomia e fisiologia, e em b) "mera psicologia empírica" (bloße empirische Psychologie) (SCHOPENHAUER, 2010, p. 49). Essa reelaboração definitiva coroa a visão schopenhaueriana segundo a qual a antropologia não se resume a seu estrato "médico" (anatômico-fisiológico) que toma a vontade como energia vital elementar, "privada de individualidade" e indistinguível de uma atividade física, vegetativa (SCHOPENHAUER, 1911-1941d, p. 25-27), ou seja, que toma o homem apenas como animalidade, como genus. Para além desse aparato, a antropologia se apresenta também como antropopsicologia, no âmbito da qual a vontade é tomada como caráter moral individualizado e o homem como personalidade, como individuum.

É a direção apontada nesse último contexto que precisa ser levada em conta, para que a noção schopenhaueriana de psicologia empírica seja compreendida em termos de observaçóes psicológicas, pois é com ela - especificamente nas últimas linhas do capítulo I do segundo tomo dos Parerga - que (embora, como já mencionamos, deixe para desenvolver apenas no capítulo XXVI da mesma obra) o filósofo abre espaço àquilo que, em suas palavras, "ainda resta" [das noch Uebrige] para além do domínio das três partes da sua metafísica (metafísica da natureza, metafísica do belo e metafísica dos costumes). Esse "resto" consistiria justamente numa espécie de conhecimento que é próprio da denominada (por ele) psicologia empírica: aquele conhecimento baseado na observação (Beobachtung) da variedade das individualidades (ou dos caracteres) que, por sua vez, permite apreender as manifestaçóes e as particularidades morais e intelectuais do gênero humano.

Alguns pontos precisam ser aqui destacados: i) para que um tal tipo de conhecimento (psicológico-moral) seja possível, a vontade não pode ser tomada apenas sob a perspectiva antropológico-médica, como mera força cega, vital e reprodutiva, que age nas functiones vitales e independe do intelecto, mas sob a perspectiva antropológico-psicológica, que a considera em sua forma 
individualizada ou personalizada; ii) esta seria a tarefa à qual caberia conhecer os "aspectos restantes" da metafísica. No entanto, o alcance desse "resto" não deixa de ser tarefa árdua, pois exige "fina observação [feine Beobachtung] e espirituosa compreensão, [e] até mesmo consideração de um ponto de vista mais elevado" (SCHOPENHAUER, 2010, p. 49), superioridade que poderia ser saboreada nos escritos daqueles espíritos privilegiados, já mencionados acima; iii) se, no entanto, transitarmos do final desse capítulo I para o capítulo XXVI da obra, captaremos uma mensagem pouco oculta, todavia, que caberia ao leitor inferir: nessa lista de "espíritos privilegiados" teria que caber ao menos mais um: o próprio Schopenhauer, não por acaso chamado por Thomas Mann (1959, p. 213) de o "psicólogo da vontade". O que se apresenta nas entrelinhas, entáo, é que, após ter saboreado aquela superioridade de seus pares, caberia finalmente a ele elaborar observaçóes psicológicas próprias, tarefa que vinha postergando - e cujo papel, enquanto isso, redefinia - desde seus escritos juvenis. Aliás, não deixa de ser significativo que, apenas na obra derradeira, e nos últimos capítulos dela, o "psicólogo da vontade" finalmente abriria alas para a sua "mera psicologia empírica”, espaço que esta jamais poderia ter ocupado antes, dado que todos os espaços - ou o próprio todo - só poderiam ser ocupados pela metafísica.

E aqui chegamos a um ponto fundamental: logo nos primeiros parágrafos de Psychologische Bemerkungen, é possível notar, de fato, que os conteúdos de tais "observaçôes" são claramente desdobramentos empíricos da vontade metafísica - sobretudo nas esferas da metafísica da natureza e dos costumes - tomada em seu poderio, tanto como princípio e sentido íntimo do mundo quanto como força que obriga os meios pelos quais atua, notadamente o intelecto, a se adequarem a ela. Vejamos:

Cada ser animal, e ainda mais o homem, necessita de uma certa adequação e proporção entre a sua vontade e o seu intelecto para poder existir e se afirmar no mundo. Ora, quanto mais esta proporção foi realizada pela natureza de modo preciso e certo, tanto mais fácil, seguro e aprazível será o caminho de um tal ser animal pelo mundo. [...] Dado que a finalidade do intelecto é a de ser lume e guia dos passos da vontade, quanto mais violento, impetuoso e passional for o impulso íntimo de uma vontade, tanto mais o intelecto que a acompanha precisará ser completo e claro para que a violência das voliçóes e das aspiraçóes, o ardor das paixóes, a tempestade dos afetos não induzam o homem ao erro, não o arrastem a açóes irrefletidas, equivocadas, desastrosas; o que acontecerá inevitavelmente se a vontade for impetuosa e o intelecto muito fraco. Ao contrário, um caráter fleumático, portanto uma vontade fraca e inerte, pode conseguir se afirmar 
com um intelecto inferior: para uma vontade moderada basta um intelecto moderado. (SCHOPENHAUER, 1911-1941f, p. 641).

No trecho a seguir, temos a admissão do filósofo de que a possibilidade de se observar claramente ou náo a vontade de vida, e, com isso, a própria viabilidade e o alcance da psicologia empírica, dependem do grau de manifestação ou de objetidade da vontade: "A vontade de vida, uma vez que constitui o núcleo íntimo de cada coisa vivente, revela-se de modo mais manifesto, e, por isso, pode ser observada mais claramente [deutlichsten beobachten] que em outra parte nos animais de espécie superior, portanto mais inteligentes." (SCHOPENHAUER, 1911-1941f, p. 642). Os graus de objetivação da vontade inferiores ao da natureza humana dificultam ou impossibilitam observações de ordem psicológica. No caso do homem, porém, se, por um lado, tal observação é facilitada, por outro, emerge com a razão a reflexão e, com esta, a capacidade de fingir que esconde ou maquia a vontade, dificultando o conhecimento da variedade das individualidades. Por isso, uma vontade individual "emerge sem véus somente nas explosóes dos afetos e das paixóes. E é justamente por isso que, toda vez que fala, a paixão é crível [...]. Pelo mesmo motivo, as paixóes são o tema principal dos poetas e o campo de batalha dos atores." (SCHOPENHAUER, 1911-1941f, p. 642).

Uma elaboração que ilustra um conteúdo recorrente dessas observaçôes psicológicas de Schopenhauer encontra-se no $\$ 306$ do capítulo dos Parerga em questão: "As angústias do espírito provocam palpitações do coração; e as palpitações do coração provocam angústias do espírito." (SCHOPENHAUER, 1911-1941f, p. 643). A ideia, por si só evidente, é a da existência de relaçóes intercambiáveis entre os domínios do fisio e do psíquico. Tristezas, preocupaçóes e inquietudes de ânimo agem de modo deprimente sobre as atividades do organismo (circulação do sangue, secreçôes, digestão etc.), tornando-as cansativas; vice-versa, se essas atividades são obstaculizadas ou obstruídas, surgem preocupaçóes, inquietudes de ânimo, "melancolia sem objeto" e, entáo, o que se chama hipocondria. Ao final desse raciocínio, a conclusão tipicamente schopenhaueriana sobre a confirmação de aspectos da sua metafísica da vontade não poderia falhar: "Não preciso dizer como tudo isso confirma a minha teoria acerca da unidade e identidade da vontade com o corpo." (SCHOPENHAUER, 1911-1941f, p. 644). E, no mais, essa espécie de observação ainda permite que entendamos melhor a afirmação do Capítulo 
I da obra em questão, a qual toma a antropologia, por um lado, como fisiologia e, por outro, como psicologia empírica.

Mas, para além da natureza fisiopsicológica dessas "observaçôes", há nelas o predomínio de um conteúdo psicológico-moral. É o que podemos notar, por exemplo, no $\$ 314$, em que o filósofo identifica no preconceito que temos a favor ou contra as pessoas as razóes pelas quais frequentemente nos enganamos a respeito do caráter delas: se encontramos alguém generoso, associamos isso a uma pessoa justa; um caráter caritativo faz-nos esperar alguém honesto; mentiras pressupóem engano. Essa nossa tendência "abre as portas para muitos erros, em parte devido à singularidade do caráter humano e em parte devido à unilateralidade do nosso ponto de vista." (SCHOPENHAUER, 1911-1941f, p. 648). Temos aqui um pressuposto metafísico e moral, que afirma ser o caráter sempre consequente e coerente, seguido por uma observação de cunho psicológico: "Mas a raiz de todos os seus atributos está situada muito profundamente para que se possa decidir com base em dados isolados quais atributos, em um determinado caso, podem coexistir e quais não." (SCHOPENHAUER, 1911-1941f, p. 648) ${ }^{11}$. Ora, o referido pressuposto metafísico diz respeito ao mencionado "resto", que não caberia à metafísica, mas que a empiricidade das açóes facultaria à psicologia "observar".

Consideraçóes dessa natureza são fartas e, com a tônica moralística que abunda nos escritos tardios, o pensador remete de modo frequente a conceitos e teses das esferas do fundamento da moral e da ética. Em alguns parágrafos, temos, inclusive, a recomendação para que o leitor confira passagens específicas da sua Ética, como no $\$ 331$, ao tratar do egoísmo moral, ou no $\$$ 335, ao abordar a definição de homem ordinário e comum enquanto ausência de caráter individual e algo restrito ao caráter da espécie: "Mais de uma vez ponderei [por exemplo, Problemas fund. d. Ética, p. 50; Mundo como V. e R., vol. I, p. 338] que, enquanto os animais não possuem senão o caráter da espécie, apenas ao homem respeita o verdadeiro e próprio caráter individual. Todavia, na maior parte dos homens há realmente pouca individualidade." (SCHOPENHAUER, 1911-1941f, p. 659).

\footnotetext{
${ }^{11}$ Podemos verificar como essa "observação" do Capítulo XXVI dos Parerga II contradiz em partes a afirmação do Capítulo VIII (Sobre a ética) do mesmo livro, que tratava da possibilidade de se conhecer o caráter de uma pessoa a partir de uma única ação a ela correspondente (cf. nota 10).
} 


\section{A psicologia empírica e as observaçóes psicológicas (Psychologische BEOBACHTUNGEN) DE RÉE}

Paul Rée, como leitor e intérprete autônomo dessa psicologia schopenhaueriana, irá adotar os traços gerais da metodologia usada por Schopenhauer em suas "observaçôes", ou seja, a ideia de elaborar uma psicologia moral descritiva. Rée (2004b, p. 3), contudo, não considera suas máximas moralísticas como intuições improvisadas, conforme temos em Schopenhauer, mas como "concentrados de pensamento" 12 , resultado de um trabalho de exame e de reflexão que pode pautar toda sorte de assuntos caros à filosofia, como aqueles da moral. E nem os propósitos e destinatários da psicologia empírica erigida por tais "observaçóes" seriam os mesmos: se, como citamos, Schopenhauer (1911-1941b, p. 81) estava certo de que o tipo de conhecimento ensejado por uma psicologia empírico-pragmática seria "efetivo e de grande utilidade para os homens do mundo" (grifo nosso), Rée (2004b, p. 65) abre um dos principais capítulos de Observaçôes psicológicas afirmando o contrário: "Observar [beobachten] os motivos das próprias ações é inútil para o homem prático; ao contrário, é assustador e danoso para a sua atividade. Mas é muito útil para o homem teorético." (grifo nosso). É que, de modo geral, podemos afirmar que Rée - por mais que Schopenhauer também tenha se lançado à tarefa similar quanto a determinados temas (como o da filosofia universitária, por exemplo) - almejava uma espécie de "desmascaramento" moral de vícios e virtudes, papel de suas máximas que, de fato, interessariam mais aos homens teoréticos que aos práticos ou (em termos schopenhauerianos) "do mundo".

Seguem-se a essas primeiras diferenças do Rée das Psychologische Beobachtungen, em relação a Schopenhauer, outras várias concepçôes da esfera conceitual, algumas similares e outras diametralmente opostas. $\mathrm{Na}$ epígrafe de abertura da obra, por exemplo, o ser humano também é, tal como no Cap. Sobre a ética dos Parerga, "o animal malvado por excelência", citação de Gobineau (L'homme est l'animal méchant par excellence) que os dois pensadores aceitam. Schopenhauer (2012, p. 55) havia dado razão a Gobineau, porque, segundo ele, "o homem é o único animal que provoca dor em um outro sem nenhum outro fim que não este mesmo”. E Rée (2004b) acompanhará a asserção schopenhaueriana de que as ações humanas são predominantemente

\footnotetext{
12 "As máximas são concentrados de pensamento que cada um pode diluir a seu gosto. Um tal estilo de escrita merece ser recomendado. Antes de tudo, com efeito, não é tão fácil dizer uma grande bobagem de forma breve. Esta, em geral, não consegue se esconder táo bem sob poucas palavras como consegue sob muitas. Ademais, grande parte da literatura torna desejável um modo de se exprimir breve." (RÉE, 2004b, p. 3).
} 
marcadas pelo egoísmo, pela inveja e pela vaidade (TREIBER, 2004, p. 436). Quanto a isso, Rée (2004b, p. 66) elabora uma série de máximas que estampam uma ironia e um pessimismo peculiares, a exemplo do que lemos nesta: "Nos lamentamos por nos tornarmos duros e malvados por causa do mundo a fim de despertarmos a crença de que somos bons por natureza". Ou nesta: "Não conhece os homens, isto é, considera-os bons." (RÉE, 2004b, p. 67).

Porém, se Schopenhauer fundou sua visão pessimista da vida na doutrina da dor do mundo e, esta, na sua concepção de vontade como algo que não é guiado pelo conhecimento, que náo se determina segundo motivos, contudo, opera cegamente, ao contrário disso, Rée não declarará a necessidade de uma concepção metafísica de mundo que reconheça a essência da realidade numa força cega, incessante e irracional. Como afirma Fazio (2010, p. 53), "para ele [Rée] é suficiente a observação psicológica que, todos os dias, o pôe diante de eloquentes exemplos de maldade e de miséria humana."

Outra constatação que expressa a natureza das diferenciaçôes entre as duas psicologias empíricas aqui tratadas diz respeito aos motivos das açóes humanas. Schopenhauer, conforme vimos, havia sustentado em sua fundamentação da moral que as motivaçóes do agir humano podem ser resumidas em três: egoísmo, maldade e compaixão. Por sua vez, Rée (2004b, p. 65) afirma: "Na base de cada ação há um mosaico de motivos, sem que saibamos de quanto egoísmo, de quanta vaidade, de quanto orgulho, de quanto medo, de quanto amor ao próximo ela é composta. O filósofo não pode, como o químico, aplicar uma análise qualitativa e quantitativa." (grifo nosso). Quanto a esse tema, porém, é preciso cautela para assumirmos que a formulação seja uma crítica fulminante e direta à tese schopenhaueriana. É que Schopenhauer diferencia motivaçóes (Triebfedern) de motivos (Motive). A formulação completa de Sobre o fundamento da moral é a seguinte: "Há em suma apenas três motivaçóes fundamentais [Grund-Triebfedern] das açôes humanas, e só por meio do estímulo delas é que agem todos os outros motivos possíveis [alle irgend möglichen Motive]." (SCHOPENHAUER, 2001, p. 137, grifo nosso).

De uma forma ou de outra, Rée segue apresentando suas disparidades em relação a Schopenhauer, o que se dará também no tratamento de outros temas, como no caso do critério schopenhaueriano para o estabelecimento da ação ética e na proposta de uma eudemonologia. A crítica mais acentuada, no entanto, não se encontra em Observaçóes psicológicas, mas em Filosofia, obra póstuma, editada em 1903, na qual o próprio pano de fundo do pensamento 
schopenhaueriano, a metafísica da vontade, é enfaticamente recusado como fantasioso:

\begin{abstract}
Que os homens e os animais queiram viver e procriar é, para Rée, um dado de fato incontestável, todavia, baseando-se sobre tal dado de fato Schopenhauer teria feito o que Rée chama "dois saltos de fantasia". O primeiro, pequeno, consiste em conceder a vontade inclusive ao mundo inorgânico. O segundo, maior e significativo, consiste em conceder a vontade também à coisa em-si: "A coisa em si também quer viver e procriar", mas assim Schopenhauer transforma a coisa em-si de Kant, que é a origem das representaçôes, na coisa em si como essência da realidade, operando aquela que Rée chama a "transfiguração da coisa em-si". (FAZIO, 2012, p. 96; RÉE, 1903 apud FAZIO, 2012, p. 96).
\end{abstract}

Essas rejeições a conceitos fulcrais de seu mestre soam, a princípio - e este é nosso ponto -, como uma espécie de reivindicação de Rée em vista de uma exigente coerência com o pretendido caráter descritivo de uma psicologia empírica como projeto filosófico: quando Schopenhauer afirma que o objeto e o tipo de conhecimento próprios de uma psicologia empírica diriam respeito a "manifestaçôes morais e intelectuais" do homem, essas "manifestaçôes" se referem necessariamente a manifestaçôes da vontade. Ora, se, em Schopenhauer, os objetos e fenômenos "descritos" pela psicologia empírica e "observados" pelo filósofo-psicólogo são sempre comprovaçóes da metafísica da vontade, em que termos a mesma espécie de objetos e fenômenos poderia ser "descrita", a partir do momento em que as principais noções de tal metafísica são recusadas ou ignoradas? Quais são, pois, as dimensôes originárias e os elementos fundamentais de uma psicologia empírica e descritiva propriamente de Rée?

Encontraremos boas respostas para essas perguntas, se nos detivermos em algumas das máximas formuladas pelo pensador, no capítulo intitulado Sobre as açóes dos homens e os seus motivos, de suas Observaçóes psicológicas. Notemos:

Máxima no 50 - "As nossas gentilezas, que parecem ser a efusão imediata do nosso afeto e da nossa bondade, são sempre o resultado de uma reflexão que conduz ao prazer individual." (RÉE, 2004b, p. 66, grifo nosso). Logo nessa sexta máxima do capítulo mencionado, é possível verificar um exemplo do que será uma característica predominante dos escritos de Rée: há, nas entrelinhas dessa "observação", ao menos duas ideias que negam ou desprezam a existência de algo que pudesse ser, em algum sentido, "metafísico" e que não se circunscrevesse ao estrito plano do interesse e do aprazível. Embora pareça, defende Rée, não há uma fonte originária donde brotariam comportamentos e gestos como o da 
gentileza. E esta não se seguiria de modo imediato de um caráter bondoso, nem seria uma decorrência necessária do fato de alguém ser bondoso, mas resultaria de uma reflexão, portanto, de algo deliberado, em vista de algum interesse individual. Para considerarmos como isso é antischopenhaueriano, basta termos presente a própria mencionada doutrina do caráter imutável e da necessidade com que as açóes se seguem dos motivos. Entretanto, também podemos retornar à tese de que afetos e paixóes são manifestaçóes do querer e movimentos da vontade individual, conforme a passagem acima citada de Sobre a liberdade da vontade (SCHOPENHAUER, 1911-1941c, p. 481).

Máxima no 90 - "Não julgamos as açôes de um homem de forma objetiva, mas as interpretamos, em sentido bom ou mau, com base na opinião boa ou ruim que já temos dele." (RÉE, 2004b, p. 71). O tema dessa máxima se revela muito similar ao do mencionado $\$ 314$ do capítulo Psychologische Bemerkungen, dos Parerga. Tanto Rée quanto Schopenhauer concordam quanto à dificuldade ou à impossibilidade de considerarmos alguém ou as ações de alguém de forma objetiva e desprovida de preconceitos. Porém, as razóes que os dois fornecem para tanto divergem substancialmente. Schopenhauer recorre à sua tese de que o fato de o caráter de alguém ser singular, consequente $\mathrm{e}$ coerente não basta para sabermos de todos os seus atributos, dado que as raízes (metafísicas e morais) de tal caráter são profundas - situam-se na "profundidade escura" da vontade - e não permitem saber, com base em dados isolados, se determinadas ações são ou não próprias de alguém. Por sua vez, Rée se limita a afirmar que a referida impossibilidade de julgamento objetivo se deve a uma questão de interpretação derivada e dependente do tipo de opinião que já temos sobre o indivíduo em questão.

Máxima no 152 - "As açôes e os eventos na vida dos homens, quando vistos do exterior, parecem muito diversos e multiformes, mas, vistos do interior, são quase todos originários de um pequeno número de instintos: do instinto de conservação e do instinto de posse, do instinto sexual ou da vaidade." (RÉE, 2004b, p. 80). Tema tipicamente schopenhaueriano, o instinto (notadamente o sexual) é tomado pelo filósofo de Frankfurt como veículo de afirmação da vontade (de vida) e da espécie, por meio da reprodução, conforme expôe a sua metafísica do amor sexual (SCHOPENHAUER, 2000). Rée, como percebemos, náo se prende à ideia de um instinto sexual enquanto afirmação de uma força volitiva da natureza, porém, entende que açóes e eventos em geral são oriundos de alguns instintos naturais. 
Máxima no 153 - "Os vícios pelos quais reprovamos o homem como indivíduo frequentemente não são características de tal homem enquanto indivíduo, mas enquanto gênero. Por exemplo: este monarca rebaixa ou eleva os seus favoritos não segundo o mérito, mas segundo o humor. Quase todo homem se comportaria assim se fosse um príncipe. Por isso, atribuímos injustamente a um determinado caráter aquilo que é consequência de determinadas circunstâncias e do caráter geral dos homens.” (RÉE, 2004b, p. 80). Se essa "observaçáo" também denota grande similaridade quanto ao tema, tratado acima, da diferenciação schopenhaueriana entre caráter individual e caráter da espécie, evidencia-se que as direções das críticas dos dois filósofos são opostas: ao invés de criticar e lamentar, como faz Schopenhauer, a ausência de uma marca individual, tida por este como o "grande mal do homem comum", Rée considera o que pode se dar no outro extremo, e nota isso em tom de consolação para quem tem atribuídos a si vícios que pertencem ao inteiro gênero: há ocasióes, a exemplo do mencionado caso do monarca, em que as características ou os caracteres individuais recebem atribuiçóes descabidas ou injustas e, por isso, o não reconhecimento do caráter genérico do homem é que se torna um malefício, contrariamente à áspera crítica de Schopenhauer.

Máxima no 184 - "Nossos princípios têm grande influência nos nomes que damos aos motivos das nossas açôes." (RÉE, 2004b, p. 83). Rée insere no rol de um tema central da metafísica da ética e do fundamento da moral schopenhauerianos (o tema dos motivos das açôes) uma "observaçâo" da esfera da linguagem ou dos limites desta, quando se trata de nomear os motivos que movem as açóes e ter certeza sobre eles. A afirmaçáo possibilita um retorno à já aludida segunda máxima do capítulo do livro de Rée em questão, que aborda o "mosaico de motivos" que estaria presente na base de cada uma de nossas açôes e que nos deixaria sem saber quais parcelas de cada um desses motivos efetivamente influenciam o ato. Mas se trata também de um tema que nos remete a uma passagem de Sobre a liberdade da vontade, em que Schopenhauer diferencia motivos sensíveis de motivos abstratos, a fim de explorar o papel da deliberação, ausente nos animais, no processo de produção da ação. Nessa ocasião, o pensador distingue classes de motivos e enfatiza o papel do cérebro e da razão como receptores da influência deles. Porém, não chega a se preocupar com o modo com que nomeamos os motivos, pois, de maneira alguma, isso alteraria - sublinhe-se - a necessidade deles na produção da ação; no máximo, seria modificada "a maneira com a qual o motivo se manifesta." (SCHOPENHAUER, 1911-1941c, p. 505-506). É notória, pois, a diferença 
em relação a Rée, o qual se interessa pelo lugar que ocupa a nomenclatura e não pela natureza (muito menos metafísica) da relaçáo entre motivos e açôes.

Máxima no 208 - "As sensaçôes [Regungen] de amor ao próximo e de benevolência, por um lado, e de inveja e de alegria maligna, por outro, não dependem mais de nós do que das sensaçôes (Regungen) de nossas vísceras." (RÉE, 2004b, p. 87). Essa "observação psicológica" também ilustra uma diferença importante entre Rée e Schopenhauer sobre importantes concepções psicológico-morais. $\mathrm{O}$ vocabulário variado em língua alemã para os termos "sentimento" e "sensação" pode facilitar nossa consideração: Rée usa o termo Regungen, comumente traduzido por "sensações" - mas que, por uma questão semântica e principalmente por remeter, no caso dessa máxima, à noção de amor ao próximo, também poderia ser entendido e traduzido como "sentimento". ${ }^{13}$ No mesmo sentido, o filósofo também usa o termo Empfindungen, o qual pode ser traduzido igualmente por "sensaçôes" ou por "sentimentos". ${ }^{14}$ Rée, portanto, tomará suas noções de amor ao próximo, de benevolência, de inveja, de alegria maligna etc. enquanto meras sensaçôes ou meros sentimentos e, com isso, ficará à vontade para afirmar serem tais sentimentos tão provenientes de "sensaçôes viscerais" quanto de "nós" (ou do nosso caráter). Frisemos: inclusive sentimentos que aduzem à noção de compaixão, motivação moral fundamental em Schopenhauer, serão, em Rée, tão dependentes de "nossas vísceras" quanto os sentimentos opostos a ela. Com isso, o autor já sinaliza para o rumo que tomariam suas concepçôes posteriores (cujo âmbito não tivemos em vista, nesta pesquisa), com um projeto de naturalização dos assuntos morais sob forte influência darwiniana. Ora, Schopenhauer, ao tratar de noçóes como a de benevolência, amor ao próximo, ou de seus opostos, como a alegria maligna, a inveja etc. chegará a tomá-los como sensações ou sentimentos. No entanto - e eis a diferenciação -, não os tomará como provenientes (ou, nos termos de Rée, "dependentes") de "sensaçôes viscerais", mas, no caso dos sentimentos altruístas, como manifestaçóes e desdobramentos de algo que não é um sentimento ou uma sensação: a própria compaixão. O filósofo da vontade (SCHOPENHAUER, 2005, \$11), o qual reservará um capítulo de sua obra magna para tratar justamente do caráter problemático do conceito de "sentimento", hesitará em definir compaixão como um mero

\footnotetext{
${ }^{13}$ Possivelmente foi esse o raciocínio que levou Fazio (2010, p. 128), em sua tradução de Psychologische Beobachtungen para o italiano, a verter a primeira ocorrência de Regungen na máxima aqui tratada como "sentimentos" e a segunda ocorrência como "sensaçôes" (sensazioni).

${ }^{14}$ Notemos que o próprio título da obra que Rée publicará posteriormente às Observaçóes psicológicas será Der Ursprung der moralischen Empfindugen (A origem dos sentimentos morais).
} 
sentimento e, para tanto, não empregará para ela nem Empfindung nem Gefühl nem Regung. A compaixão seria um fenômeno, um acontecimento que, embora cotidiano, é tomado como misterioso e até mesmo como místico, digno de ser considerado "o grande mistério da ética" (SCHOPENHAUER, 2001, p. 136). Sensaçôes ou sentimentos serão apenas aquilo que decorre desse fundamento moral familiar à fórmula mística tat-twam-asi (tu és isto) do hinduísmo.

\section{CONSIDERAÇóES FINAIS}

Paul Rée havia declarado, numa carta a Theodor Lessing (1930, p. 59): "Eu possuo um novo método [...]: observo [beobachte] todos os conteúdos da vida, mas sobretudo os costumes e os ideais dos homens, até suas molas instintivas secretas e seus bastidores. Há por detrás disso todos os âmbitos do espírito humano e também a nossa cara humanidade." Conforme mostramos, o caminho traçado por Rée para chegar a esse "novo método", em termos de filosofia moral e de psicologia empírica, no âmbito de sua obra-prima - Observaçôes psicológicas -, deu significativos passos em terrenos schopenhauerianos, senão naquele da metafísica de $O$ mundo como vontade e representação, certamente naquele dos tardios Parerga e paralipomena.

É válido ter presente, então, o conteúdo de outra correspondência que envolve Rée, uma carta que Friedrich Nietzsche (1975, p. 149) escreveu da Basileia a Erwin Rohde, em 5 de maio de 1873: "Chegou aqui para passar todo o verão um amigo de Romundt, uma pessoa muito reflexiva e dotada: um schopenhaueriano de nome Rée." (grifo nosso). Com efeito, Rée foi tratado como um schopenhaueriano por intelectuais e pensadores do seu tempo, como por Paul Deussen, por Eduard von Hartmann e por outros. Porém - é possível concluir, a partir de nossa investigação - o que há de mais schopenhaueriano nele, mesmo na fase de sua produção inicial de Observaçôes psicológicas, não vai muito além do método herdado da obra tardia do filósofo de Frankfurt, o que, nesse sentido, relativizaria o adjetivo "novo" da carta a Lessing. Se o autor esteve em sintonia com Schopenhauer quanto a algumas noçóes e teses do âmbito da moralidade, isso não é suficiente para impedir que vejamos nele um dos membros "hereges" da chamada Schopenhauer-Schule, aquele que mais exigiu coerência do "mestre" quanto a uma proposta de psicologia empírica rigorosamente descritiva. A rejeição mais cara efetuada em vista disso foi a da pedra de toque de todo o pensamento schopenhaueriano, ou seja, a da própria 
vontade como conteúdo essencial do mundo e, com ela, da própria metafísica imanente como pano de fundo desse pensamento. Afinal, como seria possível "descrever" uma ação ou uma experiência psicológica, se estas, antes mesmo da descrição, já seriam previamente e sempre manifestações de uma vontade essencial e cósmica que a tudo dá sentido? Haveria ainda o que ser "observado", se todo o conteúdo da "observaçáo" já possuísse significado próprio e prévio?

Nesse sentido, é surpreendente que, além de o verbo "observar" se fazer presente na caracterização de Rée, expressa na carta a Lessing sobre seu referido método filosófico, que parece mirar justamente os domínios dos recônditos do inconsciente humano, esse mesmo verbo não deixará de figurar também como baliza usada pelo pensador na avaliação e no "parecer final" que emite sobre seu antigo mestre, na já citada Filosofia: "Schopenhauer é um observador sutil e rico de espírito, mas não é um pensador arguto. Falta-lhe o acume filosófico de um Berkeley, de um Hume, de um Mill. Seus erros são colossais, mas ele os considera como a solução do enigma do mundo." (RÉE, 1903 apud FAZIO, 2012, p. 95-96). Para Schopenhauer, de fato, se as observaçóes psicológicas puderem ser entendidas como algum "ato filosófico" de observar os conteúdos da vida, assim como os costumes e os ideias dos homens, então elas dificilmente poderiam representar um "método novo", já que, como indicamos, terão como campo de atuação apenas o que restou da metafísica, principalmente da metafísica da ética, um "resto" que, no máximo, ensejaria uma espécie de conhecimento de fundo antropológico-moral das particularidades morais e intelectuais das individualidades, tarefa que não caberia à metafísica estabelecer.

Ademais, a investigação concentrada nos assuntos das máximas do capítulo Observaçóes psicológicas dos Parerga e paralipomena e do livro Observaçôes psicológicas, de Rée, possibilitou entender que o uso de termos alemáes diversos para "observaçóes" (Bemerkungen ou Beobachtungen), por parte dos dois pensadores, pode ser considerado um critério de distinção entre duas propostas de psicologia moral empírica apenas de forma ilustrativa. É que se, por um lado, Schopenhauer adota Bemerkungen, no título do seu capítulo, sugerindo com isso que o peso de sua metafísica da vontade, que subjaz como conteúdo e significação de todos os fenômenos - inclusive dos fenômenos psicológicos -, não permitiria o uso de Beobachtung, porque este exprime simples constataçóes de eventos e características na estrita ordem dos "fatos", por outro lado, no desenvolvimento desse mesmo capítulo, conforme vimos, o filósofo utilizará majoritariamente o termo Beobachtung, assim como o fará em outras ocasióes dos Parerga e mesmo de sua obra em geral. Ou seja, o ter- 
mo Bemerkungen é empregado apenas no título do capítulo, o que nos leva a relativizar a importância dessa distinção terminológica e questionarmos se ela foi intencional, por parte de Rée.

Porém, mais do que o mero uso de termos diferentes em alemão para o vocábulo "observaçôes", interessou-nos aqui a constatação feita de que essa escolha terminológica é ilustrativa para se pensar até mesmo a tarefa e os limites que as filosofias de cada pensador propóem a si mesmas, assim como o que significa afirmar que uma filosofia moral - ou uma psicologia empírica alicerçada em noçóes da moralidade - é descritiva. As semânticas das mencionadas "observaçóes" podem indicar, por exemplo, que, mesmo se tratando de duas filosofias morais descritivas, as quais pensam temas em comum da esfera do comportamento moral humano, como os de caráter e de motivo, tem-se duas gamas diversas de pressupostos filosóficos com os quais elas trabalham: uma "observa" os homens e o mundo com os "óculos" da metafísica imanente da vontade (embora com as particularidades da obra tardia schopenhaueriana) e outra, a partir da negação de tal metafísica e com a consequente restrição à descrição "factual" dos fenômenos cotidianos.

Numa linha que vai da rejeição, por parte de Kant, da psicologia racional wolffiana até a plena autonomia que a psicologia enquanto ciência conquista, na modernidade, é possível afirmar que Rée precisa ser tomado como um importante responsável pelo desvencilhar-se, por parte da psicologia (enquanto empírica), de pressupostos que, ao invés de facilitarem a compreensão - via Beobachtungen - das particularidades humanas, obstruiriam o caminho por serem de natureza metafísica, mesmo que esta seja assumida apenas em sentido imanente. E isso pelo fato de Rée ter sido um radicalizador das teses da pretensa moral descritiva e das Bemerkungen schopenhauerianas. Afinal, as recusas a conceitos nodais do filósofo da vontade são, conforme vimos, uma reivindicação de Rée, em vista de uma exigente coerência com o caráter autenticamente descritivo de uma psicologia empírica como projeto filosófico de fundo moral.

DEBONA, V. Bemerkungen or Beobachtungen? On the "psychological observations" of Schopenhauer and Rée. Trans/formlação, Marília, v. 42, n. 1, p. 153-178, Jan./Mar., 2019. 
ABSTRACT: This article investigates the two different models of "psychological observation" that Arthur Schopenhauer and Paul Rée elaborated as part of their moral philosophies. We intend to elucidate former's empirical psychology and the latter's critique of morality. The investigation first addresses the main concepts of the moral philosophy of Schopenhauer, so as to specify the principal aspects of his empirical psychology and its reach within his philosophy. We emphasize the descriptive - but still moral and critical - character attributed by Schopenhauer to this psychology in the sense of Psychologische Bemerkungen. Second, we discuss Rée's critique of this notion in his Psychologische Beobachtungen, a work which, even though declared by the author as being inspired by Schopenhauer, presents its "observations" with a rejection of fundamental elements of Schopenhauer's thought, especially with regard to morality.

KeYwords: Schopenhauer. Rée. Descriptive morality. Psychological observations. Empirical psychology

\section{REFERÊNCIAS}

BACELAR, K. Sobre a quarta motivação na psicologia de Schopenhauer. In: REDYSON, D. (org.). Arthur Schopenhauer no Brasil: em memória dos 150 anos da morte de Schopenhauer. Joáo Pessoa: Ideia, 2010. p. 175-196.

CIRACÌ, F.; FAZIO, D. M.; KOSSLER, M. (Hrsg.). Schopenhauer und die SchopenhauerSchule. Würzburg: Königshausen \& Neumann, 2009.

CIRACÌ, F.; FAZIO, D. M.; PEDROCCHI, F. (a cura di). Arthur Schopenhauer e la sua scuola. Lecce: Pensa Multimedia, 2007, p. 35-76. (Schopenhaueriana, 1).

FAZIO, D. M. Paul Rée: un profilo filosofico. Bari: Palomar, 2003 (Athenaeum, 35). . Paul Rée. Philosoph, arzt, philanthrop. München: Martin Meidenbauer, 2005. . La "scuola" di Schopenhauer: per la storia di un concetto. In: CIRACÌ, F.; FAZIO, D. M.; PEDROCCHI, F. (a cura di). Arthur Schopenhauer e la sua scuola. Lecce: Pensa Multimedia, 2007. p. 35-76. (Schopenhaueriana, 1).

- La scuola di Schopenhauer: testi e contesti. A cura del Centro interdipartimentale di ricerca su Arthur Schopenhauer e la sua scuola dell'Università del Salento. Lecce: Pensa Multimedia, 2009. (Schopenhaueriana, 2).

. Ein Schopenhauerianer namens Rée. In: CIRACÌ, F.; FAZIO, D. M.; KOSSLER, M. (Hrsg.). Schopenhauer und die Schopenhauer-Schule. Würzburg: Königshausen \& Neumann, 2009. p. 289-300.

. Introduzione. In: RÉE, P. Osservazioni psicologiche. A cura di Domenico Fazio. Lecce: Pensa Multimedia, 2010. (Schopenhaueriana, 4).

. A ética na escola de Schopenhauer: o caso de Paul Rée. Ethic@, Florianópolis, v. 11, n. 2, p. 87-98, 2012. 
. A escola de Schopenhauer. In: CARVALHO, R.; COSTA, G.; MOTA, T. (org.). Nietzsche-Schopenhauer: metafísica e significação moral do mundo. V. II. Fortaleza: EdUECE, 2014. p. 11-36.

FONSECA, E. R. Psiquismo e vida: sobre a noção de Trieb nas obras de Freud, Schopenhauer e Nietzsche. Curitiba: Editora da UFPR, 2012.

GURISATTI, G. Caratterologia, metafisica e saggezza: lettura fisiognomica di Schopenhauer. Padova: Il Poligrafo, 2002.

LESSING, T. Der jüdische Selbsthass. Berlin: Jüdische Verlag, 1930.

LÜTKEHAUS, L. Ein heiliger immoralist: Paul Rée (1849-1901): biographischer essay. Marburg: Basilisken-Presse, 2001.

MACHADO, B. M. A psicologia em "Humano, demasiado humano": Nietzsche, Paul Rée e a história natural da moral. 2013. 251 f. Tese (Doutorado em Filosofia) - Instituto de Filosofia e Ciências Humanas, Universidade Estadual de Campinas, Campinas, 2013. . Nietzsche e Rée: psicólogos e espíritos livres. Campinas: Editora Phi, 2016 a. - A vaidade em Paul Rée: uma questão entre Nietzsche e Schopenhauer. Voluntas: Revista Internacional de Filosofia, Rio de Janeiro, v. 7, n. 1, p. 84-104, 2016 b.

MANN, T. Leiden und Grösse der Meister. Frankfurt a. M.: Fischer Bücherei, 1959.

NIETZSCHE, F. Nietzsche Briefwechsel. Kritische Gesamtausgabe. KGB III/3. Herausgegeben von G. Colli; M. Montinari. Berlin; New York: Walter de Gruyter, 1975. PFEIFFER, E. Triangolo di lettere. Carteggio di Friedrich Nietzsche, Paul Rée e Lou von Salomé. A cura di E. Pfeiffer, ed. italiana a cura di Mario Carpitella con la collaborazione di Giuliano Campioni. Milano: Adelphi, 1999.

RÉE, P. Gesammelte Werke 1875-1885. Herausgegeben, eingeleitet und erläutert von H. Treiber. Berlin-New York: De Gruyter, 2004a.

Psychologische Beobachtungen. In: Gesammelte Werke 1875-1885.

Herausgegeben, eingeleitet und erläutert von H. Treiber. Berlin; New York: De Gruyter, 2004b.

. Osservazioni psicologiche. A cura di Domenico Fazio. Lecce: Pensa Multimedia, 2010. (Schopenhaueriana, 4).

SCHOPENHAUER, A. Sämtliche Werke. Hrsg. von Paul Deussen. 16 Bd. München: Piper Verlag, 1911-1941a. In: Schopenhauer im Kontext III - Werke,

Vorlesungen, Nachlass und Briefwechsel auf CD-ROM (Release 1/2008).

. Über die vierfache Wurzel des Satzes vom zureichenden Grunde. Auflage I. Bd. III. In: Sämtliche Werke. München: Piper Verlag, 1911-1941b.

. Über die Freiheit des Willens. In: Sämtliche Werke. Bd. III. München: Piper Verlag, 1911-1941c. 
. Der Handschriftliche Nachlass. In: Sämtliche Werke. Bd. XI. München: Piper Verlag, 1911-1941d. 1941 e.

. Briefwechsel. In: Sämtliche Werke, Bd. XIV-XVI. München: Piper Verlag, 1911-

. Parerga und paralipomena II. In: Sämtliche Werke, Bd. V. München: Piper Verlag, 1911-1941f.

. Metafísica do amor, metafísica da morte. Tradução de Jair Barboza. São Paulo:

Martins Fontes, 2000.

. Sobre o fundamento da moral. Tradução de Maria Lúcia Cacciola. São Paulo:

Martins Fontes, 2001.

. O mundo como vontade e como representação. Tomo I. Tradução de Jair Barboza.

São Paulo: Unesp, 2005.

. Sobre a filosofia e seu método [parte de Parerga e paralipomena. Tomo II].

Organização e tradução de Flamarion C. Ramos. São Paulo: Hedra, 2010.

. Sobre a ética [parte de Parerga e paralipomena. Tomo II]. Organização e tradução de Flamarion C. Ramos. São Paulo: Hedra, 2012.

. O mundo como vontade e como representação. Tomo II [Complementos]. Traduçáo de Jair Barboza. São Paulo: Unesp, 2015.

TREIBER, H. Erläuterungen. In: RÉE, P. Gesammelte Werke 1875-1885.

Herausgegeben, eingeleitet und erläutert von H. Treiber. Berlin; New York: De Gruyter, 2004. p. 385-820.

Paul Rée: eine biographische und werkgeschichtliche Skizze. In: RÉE, P.

Gesammelte Werke 1875-1885. Herausgegeben, eingeleitet und erläutert von H. Treiber. Berlin; New York: De Gruyter, 2004. p. 1-51.

Paul Rée: Nicht nur ein Freund Nietzsches. In: HOFFMANN, D. M. (Hrsg.). Nietzsche und die Schweiz. Zürich: Offizin, 1994. p. 69-83.

Recebido: $15 / 09 / 2017$

Aceito: $21 / 02 / 2018$ 